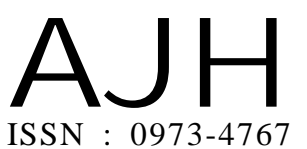

Article history :

Received : 22.04.2020

Revised : 07.05.2020

Accepted : 24.05.2020
RESEARCH PAPER

DOI : 10.15740/HAS/TAJH/15.1/7-11

\title{
Phytochemical study and in vitro propagation of Patakpura, a native Musa variety of Odisha
}

\author{
Bikram Pradhan ${ }^{1}$ and Bandita Deo
}

Members of the Research Forum

Associated Authors:

${ }^{1}$ Plant Physiology and Biochemistry Division, Regional Plant Resource

Centre, Nayapali, Bhubaneswar (Odisha) India
Author for correspondence : Bandita Deo

Plant Physiology and Biochemistry Division, Regional Plant Resource Centre, Nayapali, Bhubaneswar (Odisha) India

Email : bdeo2008@gmail.com
ABSTRACT : The presented experiments were carried out to evaluate the phytochemicals present in a Musa variety Patakpura, which is native to the coastal areas of Odisha state. Experiments were also conducted to study the effects of phytohormones such as cytokinin (BAP) and auxins (IAA) during its in vitro micropropagation. It was marked that the fruit peel, sap and stem extracts contains high phenolic and flavonoid compounds. The presence of phenolic content in high quantity caused lethal browning of explants during propagation of Patakpura. During in vitro culture it was observed that media containing high concentration of BAP $(6 \mathrm{mg} / \mathrm{L})$ had better respond in initial culture while low concentration of BAP $(3 \mathrm{mg} / \mathrm{L})$ had high bud formation in multiplication stage. Patakpura explants grown on multiplication medium supplied with $3 \mathrm{mg} / \mathrm{l} \mathrm{BAP}+0.5 \mathrm{mg} / \mathrm{L}$ IAA had highest numbers of shoot buds. In rooting culture the media containing $1.5 \mathrm{mg} / \mathrm{L}$ IAA found to be more effective in root induction.

KEY WORDS : Musa, In vitro, Phytochemical, Phytohormones, Micropropagation, Patakpura

HOW TO CITE THIS ARTICLE : Pradhan, Bikram and Deo, Bandita (2020). Phytochemical study and in vitro propagation of Patakpura, a native Musa variety of Odisha. Asian J. Hort., 15(1) : 7-11, DOI : 10.15740/HAS/TAJH/15.1/7-11. Copyright@2020 : Hind Agri -Horticultural Society 